\title{
Study on the Digital Design and Practical Application of Intangible Cultural Heritage in Anhui Province - The Case Study of Wuhu Iron Picture
}

\author{
Limin Duan, Hong Zhao
}

Anhui Institute of Information Technology, Wuhu, Anhui, 241000

Keywords: Digital Design, Intangible Culture Heritage, Wuhu Iron

\begin{abstract}
With the rapid development of modern information technology, more and more digital technology is applied to the preservation and display of intangible cultural heritage resources. The digitization of the so-called intangible cultural heritage is "the use of digital technology such as digital collection, digital storage, digital processing, digital display, digital communication and other digital technology to convert, reproduce and restore to a shared, renewable digital form and a new perspective To be interpreted in a new way to be saved and used as new needs. "It can be seen that the application of digital technology in the intangible cultural heritage is conducive to the overall protection of non-heritage, to facilitate the construction of non-heritage platform, the effective transmission, development and utilization.
\end{abstract}

\section{Introduction}

With the rapid development of modern information technology, more and more digital technology is applied to the preservation and display of intangible cultural heritage resources. The digitization of the so-called intangible cultural heritage is "the use of digital technology such as digital collection, digital storage, digital processing, digital display, digital communication and other digital technology to convert, reproduce and restore to a shared, renewable digital form and a new perspective To be interpreted in a new way to be saved and used as new needs. "It can be seen that the application of digital technology in the intangible cultural heritage is conducive to the overall protection of non-heritage, to facilitate the construction of non-heritage platform, The effective transmission, development and utilization.

Iron picture, also known as "iron flower", is the specialty of Anhui Wuhu, is one of our unique style of folk crafts. This folk art has a history of hundreds of years, the integration of Chinese painting pen and tricks, while the transmission of the Xin'an school of pen-thin simple and concise style, style, cold and stunning art style.

Non-heritage database is a core component of non-heritage protection, and its construction is to achieve non-heritage information resources integration and sharing, unified management of the important content. The non-legacy database is the result of the full use of modern information technology tools for non-heritage data, statistics, collation, cataloging and preservation. The establishment of non-heritage database is conducive to long-term preservation of non-heritage, to facilitate the public to learn and exchange, so that non-heritage is better protected and inherited. Therefore, the establishment of a scientific, complete and efficient non-legacy database is a prerequisite and basis for the effective protection of non-digitization. Cultural and creative industries rely on the wisdom of creative people 'knowledge and talent, the use of high-tech means of cultural resources for heritage and innovation, the use of intellectual property rights, developed a higher cultural value of the value of the product, to create cultural wealth and employment potential Industry) With the development of the Internet economy, China's cultural and creative industries are booming, intangible cultural heritage is the cultural and creative industries inexhaustible spiritual source, is a national economic development of soft power) for the current Internet industry resources configuration status, In the national cultural industry perspective, the immaterial cultural heritage of digital protection 'heritage and transformation, is a very urgent issue) Some domestic universities in the cultural and creative industries have made some achievements, some ideas have been transformed into cultural products, Showing its larger use of functional and cultural value) 
cultural and creative industries in academic forums and academic conferences are extremely active, set off the development of mobile Internet culture and creative industry boom.

\section{Wuhu Iron Picture Process}

Iron works of art will be the perfect combination of technology and art, after artificial intuition and create works of art. In the production process, Wuhu iron to iron on behalf of the ink to hammer belt pen to anvil, after forging, welding, drilling file, plastic, rust, baking paint, and finally mounted into a painting.

First, it is the choice of raw materials. Iron production of the use of wrought iron as raw materials, wrought iron is actually commonly known as low carbon steel. Compared with ordinary iron, wrought iron has a soft, plasticity, and greatly reduces the degree of oxidation of iron works. Secondly, is the component forging. In the construction of forging before the creation of the draft to be in-depth split, the draft split into a number of individual components, and then according to the size of each component into the furnace, into the fire smelting, re-forging molding, forging Tactics to be flexible, so as to better convey the object of the charm. Again, the components are welded and assembled. According to the original creative drawings will be forging the individual components to be assembled, and its welding molding, and more correction. With acid water will remain on the surface of the impurities in the cleaning finished, followed by drying paint, paint spray to be uniform, can not cover the pieces of the beat traces. Modern iron pictures of the anti-rust means has been greatly improved, and more to electroplating process for phosphate treatment. As the saying goes: "three points, seven mounted." So the mounting process is still important, the mounting materials and technology also have strict requirements. Some will use wool felt as the substrate, and some use of porcelain or porcelain plate, and some finally add "mirror mounted" play a dust effect.

\section{Non-Material Cultural Heritage Method}

The intangible cultural heritage refers to the traditional cultural expressions that are closely related to people's life, such as folklore performing arts traditional culture knowledge and skills, as well as related tools, physical handicrafts, etc.) Intangible culture Heritage is the majority of the working people in the production and life process of the formation of customary beliefs and cultural heritage, is the crystallization of national civilization and wisdom, reflecting the people's material and spiritual life, reflects the Chinese way of thinking values and behavior Criticism is the reality of Chinese traditional culture Professor Wang Ning of Beijing Normal University that: the intangible heritage of a high degree of personalization of the empirical and concentrated national character determines its irreplaceable uniqueness value is based on this unique Sex, can only highlight a country's personality and cultural self-confidence. From the way of inheritance, the spread of intangible cultural heritage mainly includes two dimensions. The first dimension is the inheritance of the art, that is, the communication between the artists, which is mainly the oral propaganda, this way with the inheritance of the death and survival of the change, the cultural connotation of the demise is very obvious) The inheritance of intangible cultural heritage in our country is basically the two main ways of inheritance and family inheritance, both of which face the same crisis. At this stage can be proficient in some of the traditional crafts of folk artists are mostly forty or fifty years old in the elderly, they undertake the skills of the older generation, some technology has been endangered) and the younger generation, due to economic conditions and hobbies, etc. Reason, many people do not want to engage in the inheritance of old craft, did not form the intangible cultural heritage of the protection of consciousness and awareness, leading to the preservation of intangible cultural heritage) so developed, after 15-20 years, some non-material culture The second dimension is the cultural transmission of the intangible cultural heritage). In this dimension, the paper carrier is still in the leading position, and the paper is still in the forefront of the preservation of the intangible cultural heritage, This kind of transmission determines the limited nature of the group and the speed of transmission, because the transmission channel is single, to a certain extent affect the inheritance of intangible cultural heritage, digital protection is clearly the most advanced 
method, but the establishment of the database is a kind of static protection mode, for the historical records and classification methods, is a huge revolution, how to use these data is the intangible cultural heritage to achieve the key to the status of heritage.

\section{The Strategy of Digital Protection and Inheritance of Intangible Cultural Heritage}

With regard to the digital protection and inheritance of the intangible cultural heritage, the inheritance of the intangible cultural heritage of the government alone is far from enough, and more people are concerned and concerned about the inheritance and transformation of the intangible cultural heritage. In addition to enhancing people's cultural identity of the intangible cultural heritage, the self-confidence of the national culture and the promotion of the culture of the original culture is also very important. For example, Yang Jiabu woodcut New Year paintings, ordinary people can only enjoy and appreciate the image of the meaning of New Year paintings, and the meaning of the New Year paintings and the story of which the story is not very understanding, we can see in the modern life of the lack of traditional culture is very prominent problem The There are government or civil organizations through exhibitions and exhibitions to showcase the style and achievements of folk art, can play a universal role in the knowledge of intangible cultural heritage, to improve the national intangible cultural heritage protection awareness, causing people to the intangible cultural heritage protection the attention. The advantages of this approach are obvious, but the disadvantage is a waste of human and material resources and other resources, access to relevant information channels by time and place restrictions, limited radiation.

At the national propaganda and ideological work conference, the general secretary of $\mathrm{Xi}$ Jinping proposed to strengthen the excavation and elucidation of the Chinese traditional culture, pointing out that the traditional culture is the deepest cultural soft power. It can be seen that the excavation record and inheritance of the intangible cultural heritage not only Is the continuation of the art and culture, but also the transformation of modern productive forces. Pan Lusheng presided over the arts and rural research project, from the cultural heritage industry development and rural construction perspective to explore the development of China's rural cultural industry, to explain the culture is to promote industrial development In order to protect the protection and inheritance of the intangible cultural heritage, the government should set up a special fund for the protection and inheritance of the intangible cultural heritage through the optimization and allocation of social resources and promote the diversification of the intangible cultural heritage Development, rational use of regional economy and the Internet and other advantages of resources to promote the intangible cultural heritage of the industrial transformation, so that the traditional culture in the new situation full of vitality. The government should set up leading funds to strengthen the immaterial cultural heritage of intellectual property protection, and constantly improve the relevant laws and regulations, and further promote the rationalization of the intangible cultural heritage industry and healthy development. In the face of the current situation of the development of the Internet economy, we should take active and effective measures to accelerate the development of the cultural and creative industries of the intangible cultural heritage and create more industrial value for the intangible cultural heritage.

In the Internet age, people are shopping or using any product, always want to use the product at the same time, can feel more fun and easy to buy experience. The pursuit of entertainment is the symbol of improving the quality of life, according to Maslow needs hierarchy theory, people only in the basic needs to meet the premise, there will be aesthetic needs, and now people in the original basic necessities on the basis of demand for music gradually increased. Therefore, businesses are now in the design of various products using the sales and service process have increased the degree of entertainment composition, the nature of entertainment is the respect for the user and the user experience of attention.

\section{Conclusion}

In the mobile Internet era and cultural industry perspective, people's learning and lifestyle have 
undergone tremendous changes, information dissemination has been from the books 'newspapers and other paper media transfer to the Tablet PC' mobile phone or other mobile equipment, non-material cultural heritage of digital protection and heritage will no longer stay in the collection of data, more importantly, in the realization of modern cultural products in the transformation of traditional culture to rejuvenate the new life, entertainment and product is non-material cultural heritage digital protection and heritage and make full use of the timeliness and fragmentation of mobile Internet media transmission, the protection of intangible cultural heritage into people's conscious cultural heritage behavior, in the continuous improvement of non-material cultural heritage database resources at the same time, rational allocation and use the advantages of the dissemination of the Internet, the intangible cultural heritage into the people's life and entertainment vision, into social and cultural resources, through the service industry to establish a stealth assets, so that intangible cultural heritage to live protection and heritage.

\section{Acknowledgements}

Study on the Digital Protection and Artistic Dissemination of Chinese Traditional Art - A Case Study of Wuhu Iron picture Art (Project No. SK2016A0124).

\section{References}

[1] Liu Aihe. Cultural Heritage in the field of publicity and education of the status quo and countermeasures analysis [J]. Chinese Journal of Cultural Science and Technology, 2012 (04)

[2] Zhang Guochao. Study on the construction of social education model of cultural heritage in China [J].Journal of Guizhou Normal University, (2012)

[3] Wu Yuhong. Anhui cultural and creative industry development issues [J]. East China Economic Management, 2012 (12)

[4] Ji Yong, Wang Gefei. Han clothing and the relationship between the Chinese clothing [J]. Silk, 2012 (11)

[5] Pan Zhenhua, Xu Hongkai. Mao Zedong's literary thought and its contemporary value [J]. Journal of Shandong Institute of Agricultural Administrators, 2012 (06) 